\title{
Fronto-orbital advancement and reconstruction using reverse frontal bone graft without the use of orbital bar: a technical note
}

\author{
James M. W. Robins ${ }^{1}$ - Asim J. Sheikh ${ }^{1}$ - Dmitri Shastin ${ }^{1}$ - Moritz W. J. Schramm ${ }^{1}$ - Paula Carter ${ }^{1}$. John L. Russell ${ }^{2}$ \\ Mark Liddington $^{3} \cdot$ Paul D. Chumas ${ }^{1}$
}

Received: 1 September 2019 / Accepted: 19 March 2020 / Published online: 26 March 2020

(C) The Author(s) 2020

\begin{abstract}
Introduction We describe our technique of using reverse frontal bone graft for FOAR for patients with metopic or coronal synostosis and present our complications using the Leeds classification system for complications in craniosynostosis surgery. Methods Since April 2015, seventeen patients have been operated using this technique. We perform a frontal bone graft that is then reversed, and supraorbital margins are drilled out. The orbital bar is then removed and drilled down to make bone dust and on-lay bone grafts which are then used to fill gaps on exposed dura and fill in around the temporal region.

Results All 17 patients who underwent this technique have good cosmetic results. We report 5 (29\%) complications and 8 (47\%) blood transfusions ( 7 exposures, 1 cell salvage).
\end{abstract}

Keywords Craniofacial $\cdot$ Synostosis $\cdot$ Metopic $\cdot$ Coronal

\section{Introduction}

Coronal and metopic synostosis pose a specific challenge for surgical treatment having evolved from simple suturectomy to fronto-orbital advancement and reconstruction (FOAR) $[1,2]$. Multiple FOAR techniques are described using templates for frontal bone graft [2], wire fixation or rigid metallic fixation or the use of resorbable plates. Orbital bar modifications include leaving intact, advancing the bar forward or, as demonstrated here, removing it altogether [3].

Remodelling techniques for metopic correction are recently described including the shell technique [4], cathedral dome procedure [5] and Lille's frontal reshaping and rotation of the superior and lateral orbital rim [6].

James M. W. Robins

jamesrobins@nhs.net

Paul D. Chumas

p.chumas@nhs.net

1 Department of Neurosurgery, Leeds General Infirmary, G Floor, Jubilee Building, Leeds LS1 3EX, UK

2 Department of Maxillofacial Surgery, Leeds General Infirmary, Great George St, Leeds LS1 3EX, UK

3 Department of Plastic and Reconstructive Surgery, Leeds General Infirmary, Great George St, Leeds LS1 3EX, UK
Absorbable plates offer an alternative to rigid fixation but carry higher complications [7,8]. A recent technique of orbital buttress offers an alternative to screws and plates altogether [9]. None of these techniques however addresses the problem of thinning in the bitemporal regions.

Our technique for FOAR has evolved over the years from the standard Marchac template technique, to thinning down the inner table of the orbital bar so as to be able to better reshape it [10], through to our present procedure - where the orbital bar is removed but only used for bone dust and on lay grafts. The bone dust and grafts are used to fill the temporal area to avoid future thinning and to fill gaps at exposed dura. This aids bony fusion and provides a favourable cosmetic outcome. We describe the technique, outcomes and complications of this method in a single institution.

\section{Methods}

\section{Patient selection}

All paediatric patients presenting with non-syndromic metopic or coronal synostosis since April 2015 underwent this technique in a single institution. 


\section{Surgical technique}

\section{Positioning, preparation and incision}

Patients are supine with head on horseshoe rest. Pressure areas are protected and the corneas covered with chloramphenicol antibiotic cream. The skin is prepared with aqueous iodinebased solution.

A zigzag bicoronal incision is fashioned [Leach 2004] and flaps dissected to expose orbital rims anteriorly (Fig. 1a). The pericranium is divided in the midline and taken down bilaterally with the temporalis muscle.

\section{Frontal flap marking and removal of orbital bar}

Frontal bone flap is marked and removed. The orbital bar is then removed using standard technique with the cuts along the anterior fossa floor being as close to the orbital rim as possible (Fig. 1b, c).

\section{Bone flap reversal}

Frontal bone flap is then reversed, and new orbital rims are marked and fashioned as shown. In metopic cases, the new construct is not advanced, but in coronal cases, it is advanced as far as the soft tissue envelope will allow, typically 1.5 $2.0 \mathrm{~cm}$. As this advancement is symmetrical, in cases of unicoronal synostosis, the advancement does not appear as an "over advancement" as seen in other techniques but will be significantly more advanced on the affected side. The advancement is maintained by resorbable LactoSorb plates and lag screws placed in the temporal region bilaterally and absorbable sutures to nasion (Fig. 1d).
Fig. 1 Exposure and marking a, bone flap and orbital bar marking b, markings for next cut $\mathbf{c}$, new frontal graft in place $\mathbf{d}$, frontal graft with barrel staved part $\mathbf{e}$, bone dust from removed orbital bar used to cover exposed dura $\mathbf{f}$, bone removed from orbital bar used to fill biparietal gaps $\mathbf{g}$, immediate post-op appearances $\mathbf{h}$

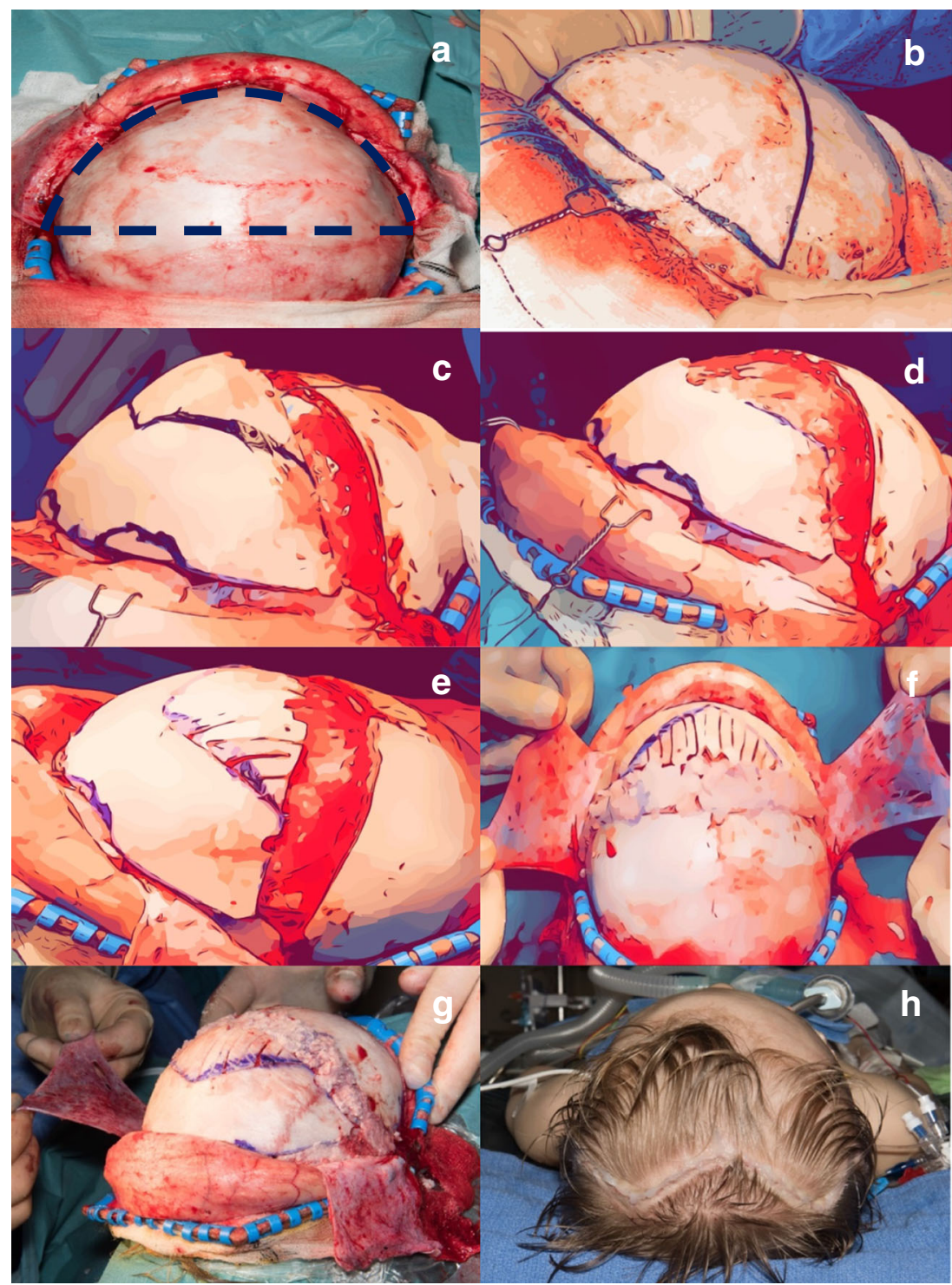




\section{Reconstruction}

The remaining bone strip is barrel staved to be placed in the gap (Fig. 1e). Bone fragments from removed orbital rim are sited temporally to prevent temporal thinning (Fig. 1f). Remaining orbital bar is drilled to bone dust and covers any remaining exposed dura (Fig. 1g). The pericranium is tacked together to help hold the construct in place.

Layered wound closure is with absorbable sutures for galea and monofilament subcuticular for skin (Fig. 1h).

\section{Results}

\section{Demographics}

Between April 2015 and March 2019, we performed this procedure in 17 non-syndromic patients ( 9 female, 8 male; age range, 12-33 months; mean age, 19.2 months). There were eight unicoronal and nine metopic synostosis. Follow-up ranged from 1 to 34 months (median 16.2 months) and length of stay ranged $2-7$ days (mean 4 days).

\section{Cosmetic outcomes}

All patients had pre- and postoperative photographs taken for comparison, and all had satisfactory cosmetic outcomes (Fig. 2). Two patients had subtle forehead recession and one patient has a slightly uneven vertex at follow-up; however, none required reoperation, and parental satisfaction was confirmed. Ophthalmological follow up did not demonstrate pulsating exophthalmos in any patients at this length of follow up.

\section{Radiological outcomes}

Whilst we used to obtain standard skull X-rays as baseline postoperatively, we have moved to specially protocolled low dose CT head with $3 \mathrm{D}$ reconstruction as routine in our institution, and this confirmed good radiological outcomes in all patients.

\section{Blood loss and transfusion exposure}

Seven patients $(41 \%)$ underwent eight blood transfusions from seven blood bags; of which, three were intraoperative (one cell salvage) and five postoperative (one patient had intraoperative and postoperative transfusion). Five patients
Fig. 2 Pre- (a-b) and post-op appearances at $18(\mathbf{f}-\mathbf{j})$ and 34 months $(\mathbf{k}-\mathbf{0})$ for unicoronal synostosis

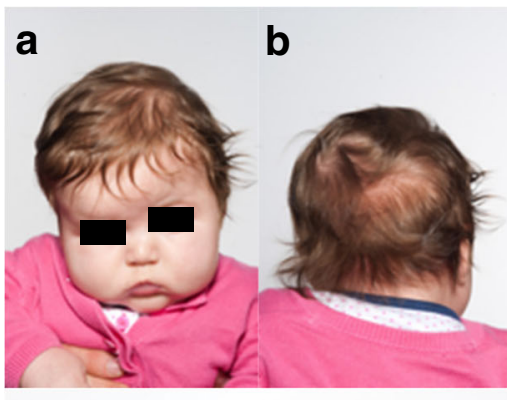

C

d

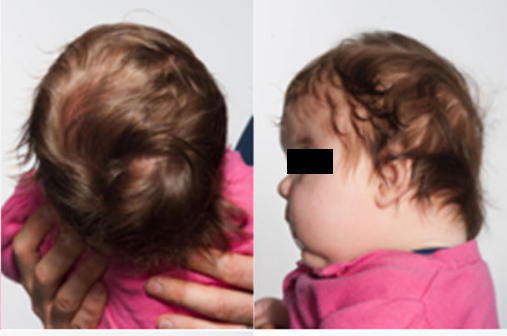

f

g

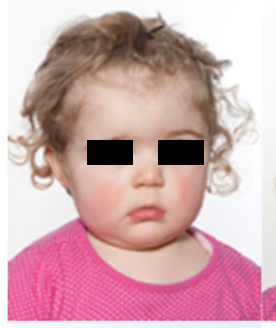

k

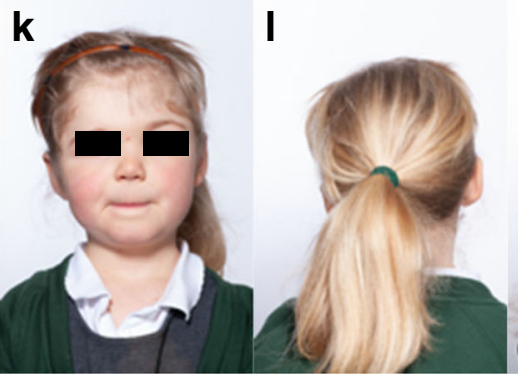

h

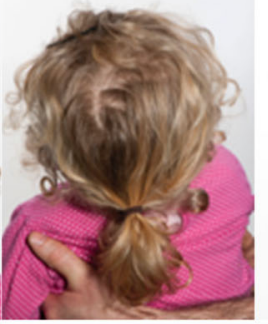

m

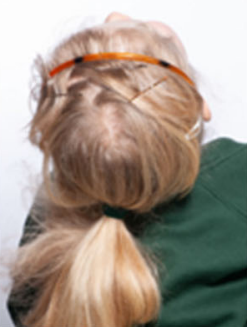

i

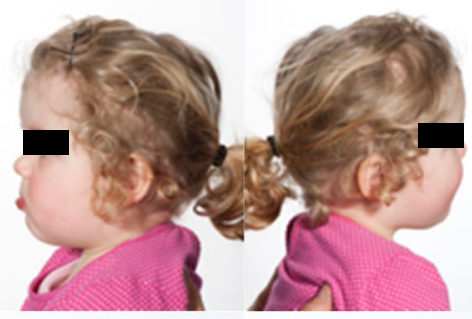

n

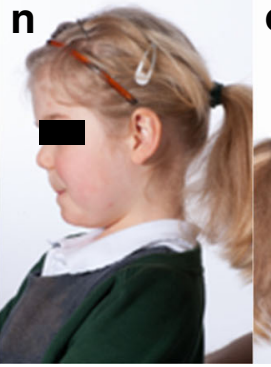

e

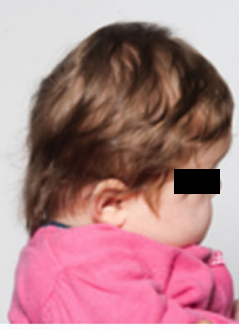

j

0

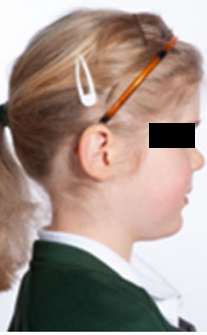


Table 1 Comparison of mean surgical time and transfusion volume between new and previous FOAR technique in our institution

\begin{tabular}{|c|c|c|c|c|c|c|c|c|c|}
\hline & \multirow[t]{2}{*}{ No of patients } & \multirow[t]{2}{*}{ Mean surgical time/h } & \multirow[t]{2}{*}{$P$ value } & \multicolumn{3}{|c|}{ Blood transfusion intra-op } & \multicolumn{3}{|c|}{ Blood transfusion post-op } \\
\hline & & & & No. & Mean volume & $P$ value & No. & Mean volume & $P$ value \\
\hline Robins et al & 17 & $3: 33$ & 0.32 & 3 & $11.84 \mathrm{ml} / \mathrm{kg}$ & 0.094 & 5 & $13.67 \mathrm{ml} / \mathrm{kg}$ & 0.467 \\
\hline Shastin et al & 40 & $3: 23$ & & 21 & $17.50 \mathrm{ml} / \mathrm{kg}$ & & 11 & $15.08 \mathrm{ml} / \mathrm{kg}$ & \\
\hline
\end{tabular}

(29\%) received a sodium feredetate only, whilst one received sodium feredetate and intraoperative transfusion and, one combined with a postoperative transfusion. In the previous results in our institution [11], 31 patients $(78 \%)$ underwent blood transfusion ( 2 cells salvage) of which 21 were intraoperative $(52.5 \%)$ and 11 postoperative $(27.5 \%)$. Again, one patient had intra- and postoperative transfusion. There was no difference in volumes transfused intra- and postoperatively ( $\mathrm{p} \mathrm{0.094,} \mathrm{p} \mathrm{0.467)} \mathrm{in} \mathrm{ml} / \mathrm{kg}$ between studies; however, there was almost a significant decrease (p 0.0551) in total blood volume transfused in this new technique compared with the previous technique used in our unit (Table 1).

\section{Surgical time}

Theatre time from incision to closure ranged from 3:01 to 4:31 h (mean 3:33 h, median 3:30 h). Note no significant increase in time compared with the previous technique used in our institution (Table 1).

\section{Complications}

There were no mortalities; however, five patients (29\%) experienced complications.

One patient experienced a dural tear, repaired intraoperatively, and then subsequently represented with a culturepositive wound infection (Salmonella sp.). This required four washouts and IV antibiotics. One patient suffered some bloodstained vomit managed conservatively with no increased length of stay. Three patients had slight forehead recession or an uneven vertex; however, none required reoperation. Complications along with their Leeds classification of complications in craniosynostosis surgery are demonstrated in Table 2 [11].

\section{Discussion}

Surgical treatment for craniosynostosis continues to evolve. Original techniques involved strip craniectomy; however, this did not address cranio-orbital deformities [12]. Simple suturectomy does not address orbitocranial deformity or associated risk. Subsequently fronto-orbital advancement was shown to be a safe technique [2] and was refined to correct skull base deformity and improve cosmetic outcomes [13].

Thornett et al. presented a FOAR series without removal of orbital bar in 2016 [14]. We present a similar technique but with orbital bar removal. We remove the frontal bone via bifrontal craniotomy and reverse it. New orbital rims are fashioned in this graft and removed orbital bar fills bitemporal gaps. This aims to prevent graft torsion and future biparietal thinning. The remaining bone is drilled providing bone dust to cover exposed dural surfaces and promote fusion. In our experience, this results in good cosmetic outcomes-including in the temporal region, frequently a problem in other techniques, especially metopic synostosis. We found no persistent temporal "thinning" in our series; however, this may only be evident at prolonged follow-up, and thus this limits our conclusions. We did notice two examples of mild forehead recession despite advancing the orbital rim as far as soft tissue envelope allowed. Again, we accept that follow-up is still limited - although the case of unicoronal synostosis in Fig. 2 shows a good result at 34 months. It may be that the risk of late recession is reduced by the use of the bone originating from a

Table 2 Demonstration of complications and classification using Leeds classification of complications in craniosynostosis compared with Oxford classification [11]

\begin{tabular}{|c|c|c|c|}
\hline Complication & No. of patients & Leeds classification & Oxford classification \\
\hline Wound infection & 1 & $\begin{array}{l}3 \mathrm{C} \text { - Complications requiring readmission. } \\
\text { Surgical } 30 \leq \text { days since discharge }\end{array}$ & 3-Reoperation but no long-term sequelae \\
\hline Blood-stained vomit & 1 & 1A-Inpatient complication with normal LOS & $\begin{array}{l}\text { 1- No delay in discharge, } \\
\text { reoperation or long-term sequelae }\end{array}$ \\
\hline Slight forehead recession & 2 & 2B - Outpatient complications not requiring readmission & $\begin{array}{l}\text { 1- No delay in discharge, re } \\
\text { operation or long-term sequelae }\end{array}$ \\
\hline Uneven bumpy vertex & 1 & 2B-Outpatient complications not requiring readmission & $\begin{array}{l}\text { 1- No delay in discharge, } \\
\text { reoperation or long-term sequelae }\end{array}$ \\
\hline
\end{tabular}


different region. Likewise, it is of note that transposition of different cells from orbital bar to another skull region does not result in mucocele formation, provided grafted bone does not contain frontal sinus precursor cells [15].

We also present a low rate of complications in this initial small series and demonstrate these using a craniosynostosis classification system [11]. We show no difference in volume of intra- and post-op blood transfusion compared with the previous work; however, there is almost a significant decrease in total blood volume transfused (intra- and post-op combined) [11] suggesting a possible impact from newly using intraoperative tranexamic acid in all patients in this series. This is likely to be significant in a larger case series. Of note is that there was no difference in operative time using this new technique. Length of stay was on average 4 days, comparable with previous findings.

\section{Conclusion}

We demonstrate a novel technique of FOAR for metopic and coronal synostosis. Our low complication rate shows that it is safe to remove orbital bar, utilising it as bone dust to fill temporal gaps. This achieves forehead flattening, minimal frontal bone flap torqueing and appropriate advancement with prevention of parietal thinning at this limited length of follow-up.

Open Access This article is licensed under a Creative Commons Attribution 4.0 International License, which permits use, sharing, adaptation, distribution and reproduction in any medium or format, as long as you give appropriate credit to the original author(s) and the source, provide a link to the Creative Commons licence, and indicate if changes were made. The images or other third party material in this article are included in the article's Creative Commons licence, unless indicated otherwise in a credit line to the material. If material is not included in the article's Creative Commons licence and your intended use is not permitted by statutory regulation or exceeds the permitted use, you will need to obtain permission directly from the copyright holder. To view a copy of this licence, visit http://creativecommons.org/licenses/by/4.0/.

\section{References}

1. Hunter AGW, Rudd NL (1976) Craniosynostosis. I. Sagittal synostosis; its genetics and associated clinical findings in 214 patients who lacked involvement of the coronal suture(s). Teratology 14(2): 185-193

2. Marchac D (1978) Radical forehead remodeling for craniostenosis. Plast Reconstr Surg 61(6):823-835

3. Whitaker LA, Schut L, Kerr LP (1977) Early surgery for isolated craniofacial dysostosis. Improvement and possible prevention of increasing deformity. Plast Reconstr Surg 60(4):575-581

4. Di Rocco C, Frassanito P, Tamburrini G (2013) The shell technique: bilateral fronto-orbital reshaping in trigonocephaly. Childs Nerv Syst 29(12):2189-2194

5. Pang D, Zovickian J, Wong S, Hou YJ, Le HN (2013) Parallel angulated frontal bone slat cuts for treatment of metopic synostosis and other frontal skull deformities: the \&quot;cathedral dome procedure\&quot. Childs Nerv Syst 29(12):2171-2182

6. Pellerin P, Vinchon $\mathrm{M}$, Dhellemmes P, Wolber A, Guerreschi P (2013) Trigonocephaly: Lille's surgical technique. Childs Nerv Syst 29(12):2183-2188

7. Pearson GD, Havlik RJ, Eppley B, Nykiel M, Sadove AM (2008) Craniosynostosis: a single institution's outcome assessment from surgical reconstruction. J Craniofac Surg 19(1):65-71

8. Sanger C, Soto A, Mussa F, Sanzo M, Sardo L, Donati PA, Di Pietro G, Spacca B, Giordano F, Genitori L (2007) Maximizing results in craniofacial surgery with bioresorbable fixation devices. J Craniofac Surg 18(4):926-930

9. Seal SKF, Steinbok P, Courtemanche DJ (2015) The cranial orbital buttress technique for nonsyndromic unicoronal and metopic craniosynostosis. Neurosurg Focus 38(5):E4

10. Carter LM, Varley I, Smith IM, Chumas P, Liddington M, Russell JL (2013) Inner table corticectomy of the fronto-orbital bar in correction of metopic and coronal craniosynostoses. J Craniofac Surg 24(1):195-196

11. Shastin D, Peacock S, Guruswamy V et al (2017) A proposal for a new classification of complications in craniosynostosis surgery. $\mathrm{J}$ Neurosurg Pediatr 19(6):675-683

12. Shillito J, Matson DD (1968) Craniosynostosis: a review of 519 surgical patients. Pediatrics 41(4):829-853

13. McCarthy JG (1979) New concepts in the surgical treatment of the craniofacial synostosis syndromes in the infant. Clin Plast Surg 6(2):201-226

14. (2016) Proceedings of the 2016 Spring Meeting of the Society of British. Br J Neurosurg 30(2):130-186

15. Yoon SH, Park S-H (2007) Delayed development of frontal mucocele after fronto-orbital advancement in a child with craniosynostosis. Surg Neurol 67(5):517-521

Publisher's note Springer Nature remains neutral with regard to jurisdictional claims in published maps and institutional affiliations. 